of specialized multidisciplinary institutes, both within the university and with government or corporate partners, is described in detail.

US universities with a strong science and engineering base have gone the farthest down this route. This trend is reflected in the book, which somewhat under-represents the role of arts and humanities faculty in creating partnerships and innovation. The pace of innovation may be slowed in universities that are governed from the bottom-up by faculty, whereas it is more likely to be pushed by governing bodies that have a majority of external members.

Tapping the Riches of Science focuses on the large and diverse US university system. I would like to see this study extended to consider the effects of globalization. Not all university systems are as well placed to be a partner in global consortia. For example, entrepreneurial faculty may fare better in the independent universities of the United Kingdom compared with those in Japan or many countries in Europe, where

\title{
Bringing clarity to complexity
}

\section{Complexity: A Guided Tour \\ by Melanie Mitchell \\ Oxford University Press: 2009. \\ 368 pp. $€ 14.99, \$ 29.95$}

For several decades, scientists studying complex systems - rich, collective systems such as ant colonies, economies and cells - have spoken of 'emergence', the mysterious process by which the collective whole acquires resilience, adaptability and other surprising properties, even though its components are simple. The archetypal example is the ant colony, which manages to forage intelligently for food and organize collective defence by exploiting the limited skills of its individual ant citizens.

The ideas of complexity have spread across science, and emergence has become a buzzword. Philosopher Mark Bedau has suggested, however, that it poses a puzzle, as it demands that two seemingly contradictory statements must be true. In complex systems, organized phenomena at higher levels depend on processes at lower levels: everything in a cell, for example, depends on the processes of atomic physics. Yet phenomena emerging at higher levels gain autonomy from lower levels: the body's organs and their interactions can be described and explained without reference to atomic physics.

How can something be dependent and autonomous at the same time? And why do so many systems in nature show this hierarchical professors are essentially civil servants.

Moreover, it is the global problems that are coming to the fore - overpopulation, poverty, climate change, financial instability and inequity. In 20 years, I anticipate that a similar book will describe how universities in different global consortia will have succeeded in getting their institutional arms around these complex problems. Providing global solutions will involve a greater proportion of the faculty, not just from science and engineering, necessarily working in multidisciplinary teams. Such collaboration will further erode Cardinal Newman's nineteenth-century vision of a university as a self-governing community of disinterested scholars.

Michael Kelly is chief scientific adviser to the UK Department for Communities and Local Government, and the Prince Philip Professor of Technology in the Department of Engineering, University of Cambridge, Cambridge CB3 OFA, UK. e-mail:mjk1@cam.ac.uk organization? No one has answered these questions, but in Complexity, computer scientist Melanie Mitchell of the Santa Fe Institute, New Mexico, offers a valuable snapshot of the growing field of complex-systems science from which the answers may eventually arise.

Mitchell explores the historical roots of this area in the work of visionaries such as Henri Poincaré and Edward Lorenz in dynamicalsystems theory, and of John von Neumann, Alan Turing and others in computation. The unifying feature of complex systems, Mitchell emphasizes, is that systems as diverse as cells, economies and ecosystems, as well as the human brain, all process information, and do so in a way that makes them rich, adaptable and hard to understand. The book hits its stride in its latter half, with an insightful survey of recent developments in complex-network theory and scaling in biology.

Especially valuable is the book's exploration of recent attempts to categorize the dynamics of cellular automata - simple systems that act as models for the study of rich dynamics. Some of this work, under the name of computational mechanics and linked to the ideas of Mitchell's former colleague, the late Jim Crutchfield, probes the fundamental 'information physics' of complex systems in general. This focus of the book is commendable, as much of the literature of complex-systems research dwells on more expansive philosophical themes at the expense of the 'boring' details of specific models. Yet intense scrutiny of such models may ultimately reveal clues to solving Bedau's mystery.

Mitchell touches on the many practical applications of this science, ideas put into practice by forward-looking companies such as Cisco and Capital One. The book is timely, given that many analyses of the present financial crisis have concluded that the key issue is how markets have outstripped our ability to understand them.

It has become fashionable in recent years to criticize complex-systems science for generating too much hype and not offering enough practical insight. But insights into truly complex problems do not come easy. Mitchell's welcome book makes it clear that this field is making steady, if slow, progress.

Mark Buchanan is a writer based in the United Kingdom and author of The Social Atom. e-mail: buchanan.mark@gmail.com

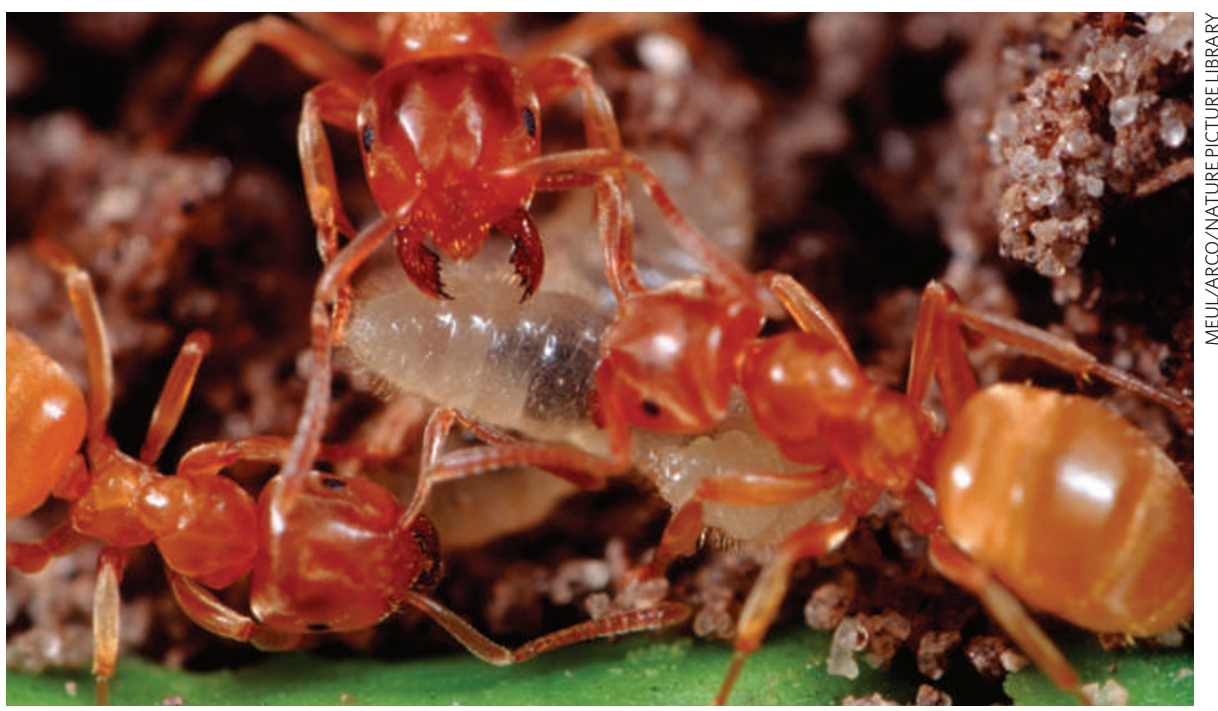

As a colony, ants perform complex tasks that individuals could not achieve alone, such as tending larvae. 